\title{
Evaluation of Selective Harmonic Elimination Pulse Width Modulation Technique for Unipolar Single-Phase H-Bridge Inverter: Comparative Study
}

\author{
Hussain Attia \\ Electrical, Electronics \& Communication Engineering Dept., American University of Ras Al Khaimah \\ American University of Ras Al Khaimah, Uni Emirat Arab
}

\begin{tabular}{l} 
Article Info \\
\hline Article history: \\
Received Dec 13, 2017 \\
Revised May 10, 2018 \\
Accepted Jul 1, 2018 \\
\hline
\end{tabular}

Keyword:

Fundamental component Load power

MATLAB

Nonlinear equations

Selective harmonic elimination

Switching angles

Total harmonics distortion

Unipolar h-bridge inverter

\section{Corresponding Author:}

Hussain Attia,

Electrical, Electronics \& Communication Engineering Dept.,

American University of Ras Al Khaimah,

Ras Al Khaimah, 10021, Uni Emirat Arab

Email: hattia@aurak.ac.ae

\begin{abstract}
In this paper, a detailed comparative study about evaluating the single-phase inverter performance based on selective harmonic elimination pulse width modulation (SHE PWM) technique is presented. Set of nonlinear equations are derived, four groups of switching angles are calculated using the numerical iterative method of Newton-Raphson. These angles are representing the ideal solutions to eliminate the low order harmonics from inverter output voltage and load current. Inverter effectiveness is evaluated by comparing the performance based on SHE PWM and based on the conventional constant switching frequency PWM (CSF PWM) technique. Same parameters setting is selected with considering the constant switching frequency value for each case separately as equivalent to the number of switching angles. Moreover, different rated load powers are investigated to explain the merit of SHE PWM within high power applications. MATLAB / Simulink simulation results are clearly indicating the priority of the SHE PWM at all groups of calculated angles and at different load power as well.
\end{abstract}

Copyright $@ 2018$ Institute of Advanced Engineering and Science. All rights reserved.

\section{INTRODUCTION}

Effective inverter is characterized by only low current total harmonic distortion (THD), and low switching losses for improved efficiency [1]-[3]. Pulse Width Modulation (PWM) based inverters (single phase and three phase) and PWM based DC-DC converters are widely constructed and used because of the simplicity of the PWM drive pulses generation, whereas to have better THD level of load current, the value of switching frequency needs to be increased. On the other hand, high switching frequency represents a tradeoff within switching losses in the inverter switches and THD that leading to the difficulty to use for high power applications due to the switching losses limitation [4]-[8].

So there is limitation of using constant switching frequency pulse width modulation (CSF PWM) or carrier modulated PWM (CPWM) like Sinusoidal PWM (SPWM) for high power applications due to the limitations of switching frequency and switching losses. Selective Harmonic Elimination Modulation (SHEM) represents one of precalculated programmed PWM (PPWM) that it represents an effective alternative. The principle of SHEM adopts choosing the switching angles based on the desired harmonics to remove from the fundamental waveform [9]. The merits of SHEM based inverter over CSFPWM based inverter can be briefed by lower switching losses due to the lower number of commutations of inverter's 
switches per reference cycle, suitability for high power applications due to the lower switching losses which leading to lower stress on the system's switches, high power conversion from the DC link supply voltage due to the possibility of designing the working conditions of over modulation, possibility of using lower DC link capacitor due to the low ripple in the DC link supply current, , capability of using GTO thyristors for high power applications due to the lower number of switches' commutations per reference cycle, canceling the low order harmonics removes the possibility of resonance with low frequency devices such as line filters [10]-[20].

In [10], A single phase converter is presented based using SHEM based on Unified Power Flow Controller (UPFC), the converter eliminates the low order harmonics of 5th 7th 11th and 13th by off line calculating the switching angles of 10 different modulation indices using Genetic Algorithm. The converter performance is evaluated by comparing with the sinusoidal PWM (SPWM) based converter, and the comparison demonstrated that the SHEM based converter is completely eliminated the four low order harmonics. For induction motors feeding three phase PWM inverter applications, harmonic elimination process in presented in [11] based on particle swarm optimization (PSO). Nonlinear transcendental equations are presented to have accurate selective harmonics elimination up to the 23rd order from the waveform of inverter voltage. The precise solutions are obtained after several iterations of the particle swarm algorithm converging process and the low order harmonics are successfully attenuated. Selective harmonic elimination is done in [12] based on PWM modulation technique by which the carrier waveform is modified based on a certain process instead of numerical process of optimization. The method is evaluated in [12] by comparing with carrier pulse width modulation.

An optimum switching patterns generations presented in [13] for voltage controlled inverter applications. In this study, 8 notch angles are determined based on neural network method for different modulation indices to eliminate the low order harmonics till including the 22th harmonic. Simulation results confirmed the fully elimination of the mentioned harmonics. A certain SHEPWM technique is proposed in [14], [15] to generate PWM pulses for inverter gate driving based on Resultant method. This method solves a set of nonlinear equations to identify and determine the switching angles. PWM pulses are driving a fullbridge single-phase inverter's switches through unipolar strategy without needing of the initial guess.

Novel five levels voltage source inverter (VSI) is presented in [16] based on SHEPWM technique. Set of nonlinear equations are solved to determine the switching angles through high convergence speed numerically process. Simulation results demonstrate the advantage of SHE PWM over the conventional PWM. In [17], [18], the optimization process of the differential evolution method is adopted to determine the optimized positions of the switching angles as an objective of SHE PWM technique whereas the concept of Artificial Neural Networks (ANN) is proposed in [19] to optimize the switching angles positions determination to be used for H-bridge inverter's switches gates driving.

In this paper, the SHE PWM technique angles generation and process execution are explained in details, and then the inverter performance effectiveness is evaluated by comparing with the conventional constant switching frequency PWM (CSF PWM) technique. The numerical technique of Newton-Raphson [20] is adopted through offline iterative process to determine different strings of angles for different modulation indices, all these values are saved in look-up tables (LUT) within MATLAB/Simulink program. The comparisons are done by analyzing load voltage and current waveforms, Total Harmonic Distortion (THD) as well as harmonic spectrum particularly at low order harmonics at different load power. For precise evaluation, the equivalent CSF PWM switching frequency is selected for each comparison individually based on the number of switching angle of SHE PWM technique. The analysis indicates the highly priority of SHE PWM over CSF PWM especially for high level of power applications.

\section{SWITCHING ANGLES DETERMINATION}

The method of Newton-Raphson is adopted to determine the positions of the single-phase H-bridge inverter's switches switching angles for the aim of eliminating the low order harmonics of different angles strings as follows; (3th, 5th), (3th, 5th, 7th, 9th, 11th), (3th, 5th, 7th, 9th, 11th, 13th), and (3th, 5th, 7th, 9th, 11 th, 13th, 15th, 17th) at range of modulation index (MI) values. For the first string of switching angles $(\varnothing 1$, $\emptyset 2$, and $\emptyset 3$ ) which will be determined by iteration method using Newton Raphson algorithm process [20], this process is started from Eq. (1), obtaining the set of the nonlinear equations, and then solve these equations set. Same process is repeated to have the other solutions of the other angles sets for extra low order harmonics elimination. Figure 1 shows the topology of the inverter which adopted the unipolar PWM strategy in order to reduce the stress on the inverter's switches [1], [2]. For SHE PWM, Figure 2 shows the shape of the load voltage $\left(V_{A O}\right)$ which explains five switching angles.

Due to wave symmetry quarter waveform [21]; 


$$
V_{A O}(\omega t)=\sum_{n=1}^{\infty} b_{n} \sin (n \omega t)
$$

where $b n=0$ for even $n$, whereas for odd $n$;

$$
b_{n}=\frac{4}{\pi} \int_{0}^{\frac{\pi}{2}} V_{s} \sin (n \omega t) d(\omega t)
$$

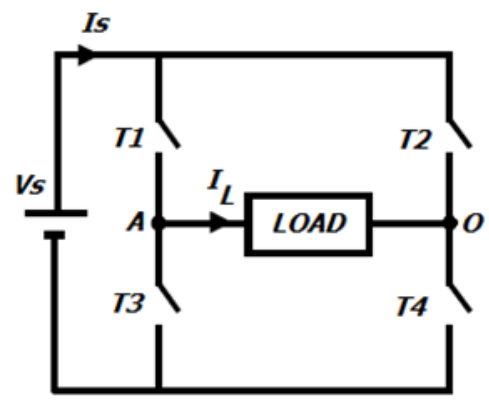

Figure 1. H-bridge single phase inverter 1

Total Harmonics Distortion (THD) can be calculated using Eq. (3);

$$
T H D=\frac{\sqrt{\sum_{n=2}^{\infty} V_{n}^{2}}}{V_{1}}
$$

where $V_{l}$ is the first fundamental component while $V_{n}$ are the above harmonic components [14].

For the notches of the five angles of $\emptyset_{1}, \emptyset_{2}, \emptyset_{3}, \emptyset_{4}$, and $\emptyset_{5}$, which are; $0 \leq \emptyset_{1} \leq \emptyset_{2} \leq \emptyset_{3} \leq \emptyset_{4}, \leq \emptyset_{5} \leq \frac{\pi}{2}$, the value of $b_{n}$ can be calculated as follows;

$$
\begin{aligned}
& b_{n}=\frac{4}{\pi}\left(\int_{\emptyset_{1}}^{\emptyset_{2}} V_{s} \sin (n \omega t) d(\omega t)+\int_{\emptyset_{3}}^{\emptyset_{4}} V_{s} \sin (n \omega t) d(\omega t)+\int_{\emptyset_{5}}^{\frac{\pi}{2}} V_{s} \sin (n \omega t) d(\omega t)\right) \\
& b_{n}=\frac{4 V_{S}}{n \pi}\left([-\cos (n \omega t)]_{\emptyset_{1}}^{\emptyset_{2}}+[-\cos (n \omega t)]_{\emptyset_{3}}^{\emptyset_{4}}+[-\cos (n \omega t)]_{\emptyset_{5}}^{\frac{\pi}{2}}\right) \\
& b_{n}=\frac{4 V_{S}}{n \pi}\left([-\cos (n \omega t)]_{\emptyset_{1}}^{\emptyset_{2}}+[-\cos (n \omega t)]_{\emptyset_{3}}^{\emptyset_{4}}+[-\cos (n \omega t)] \begin{array}{c}
\frac{\pi}{2} \\
\emptyset_{5}
\end{array}\right)
\end{aligned}
$$

Due to $\mathrm{n}$ is odd during the analysis and the determination of $b_{n}$, so

$$
\begin{aligned}
& {[-\cos (n \omega t)]=0} \\
& b_{n}=\frac{4 V_{S}}{n \pi}\left[\cos \left(n \emptyset_{1}\right)-\cos \left(n \emptyset_{2}\right)+\cos \left(n \emptyset_{3}\right)-\cos \left(n \emptyset_{4}\right)+\cos \left(n \emptyset_{5}\right)\right]
\end{aligned}
$$

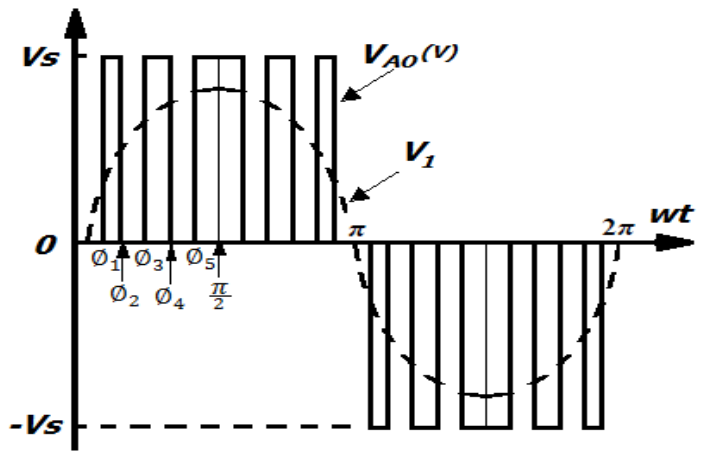

Figure 2. Selective Harmonic Elimination Pulses with Unipolar PWM strategy 
In other words to keep only first harmonic $\left(V_{l}\right)$ and remove the odd multiple of it, Eq. (7) can be rewrite in Eq. (8) as shown within the nonlinear equations;

$$
\begin{aligned}
& \frac{4 V s}{\pi}\left[\operatorname{Cos}\left(\emptyset_{1}\right)-\operatorname{Cos}\left(\emptyset_{2}\right)+\operatorname{Cos}\left(\emptyset_{3}\right)-\operatorname{Cos}\left(\emptyset_{4}\right)+\operatorname{Cos}\left(\emptyset_{5}\right)\right]=V_{1} \\
& \operatorname{Cos}\left(3 \emptyset_{1}\right)-\operatorname{Cos}\left(3 \emptyset_{2}\right)+\operatorname{Cos}\left(3 \emptyset_{3}\right)-\operatorname{Cos}\left(3 \emptyset_{4}\right)+\operatorname{Cos}\left(3 \emptyset_{5}\right)=0 \\
& \operatorname{Cos}\left(5 \emptyset_{1}\right)-\operatorname{Cos}\left(5 \emptyset_{2}\right)+\operatorname{Cos}\left(5 \emptyset_{3}\right)-\operatorname{Cos}\left(5 \emptyset_{4}\right)+\operatorname{Cos}\left(5 \emptyset_{5}\right)=0 \\
& \operatorname{Cos}\left(7 \emptyset_{1}\right)-\operatorname{Cos}\left(7 \emptyset_{2}\right)+\operatorname{Cos}\left(7 \emptyset_{3}\right)-\operatorname{Cos}\left(7 \emptyset_{4}\right)+\operatorname{Cos}\left(7 \emptyset_{5}\right)=0 \\
& \operatorname{Cos}\left(9 \emptyset_{1}\right)-\operatorname{Cos}\left(9 \emptyset_{2}\right)+\operatorname{Cos}\left(9 \emptyset_{3}\right)-\operatorname{Cos}\left(9 \emptyset_{4}\right)+\operatorname{Cos}\left(9 \emptyset_{5}\right)=0
\end{aligned}
$$

Initial angles of a single-phase unipolar SHE PWM inverter based on [22]:

$$
\emptyset_{k}=\frac{180 \times k}{2 N+1}
$$

where $\mathrm{k}=1,2,3, \ldots \mathrm{N}$; and $\mathrm{N}$ : number of angles, the initial value of the five angles is as shown below whereas the solutions of these angles based on Newton-Raphson Method [20] through five iteration process for different modulation indices are shown in Table 1;

$$
\emptyset^{0}{ }_{1}=16.36^{\circ}, \emptyset_{2}^{0}=32.73^{\circ}, \emptyset^{0}{ }_{3}=49.1^{\circ}, \emptyset^{0}=65.45^{\circ}, \emptyset^{0}{ }_{5}=81.8^{\circ}
$$

Figure 3 shows four strings of angles which represent as a selective harmonics elimination solution at different modulation indices.

Table 1. Angle solutions for harmonics elimination based on Newton-Raphson Method

\begin{tabular}{cccccc}
\hline MI & $\emptyset 1$ & $\emptyset 2$ & $\emptyset 3$ & $\emptyset 4$ & $\emptyset 5$ \\
\hline 0.01 & 29.9249 & 30.0749 & 59.8699 & 60.1297 & 89.8500 \\
0.035 & 29.7295 & 30.2543 & 59.5416 & 60.4511 & 89.4749 \\
0.10 & 29.2308 & 30.7287 & 58.6819 & 61.2807 & 88.4983 \\
0.15 & 28.8396 & 31.0830 & 58.0115 & 61.9109 & 87.7447 \\
0.20 & 28.4385 & 31.4228 & 57.3295 & 62.5310 & 86.9873 \\
0.25 & 28.0310 & 31.7500 & 56.6367 & 63.1421 & 86.2248 \\
0.30 & 27.6172 & 32.0631 & 55.9321 & 63.7437 & 85.4557 \\
0.35 & 27.1975 & 32.3604 & 55.2143 & 64.3347 & 84.6779 \\
0.40 & 26.7718 & 32.6396 & 54.4818 & 64.9137 & 83.8892 \\
0.45 & 26.3401 & 32.8983 & 53.7327 & 65.4787 & 83.0866 \\
0.50 & 25.9024 & 33.1333 & 52.9645 & 66.0266 & 82.2666 \\
0.55 & 25.4581 & 33.3408 & 52.1744 & 66.5535 & 81.4241 \\
0.60 & 25.0067 & 33.5160 & 51.3586 & 67.0530 & 80.5523 \\
0.65 & 24.5473 & 33.6530 & 50.5122 & 67.5161 & 79.6413 \\
0.70 & 24.0785 & 33.7436 & 49.6289 & 67.9281 & 78.6760 \\
0.75 & 23.5980 & 33.7772 & 48.6998 & 68.2649 & 77.6321 \\
0.80 & 23.1019 & 33.7381 & 47.7118 & 68.4834 & 76.4669 \\
0.85 & 22.5835 & 33.6015 & 46.6433 & 68.4980 & 75.0978 \\
0.90 & 22.0275 & 33.3203 & 45.4513 & 68.1123 & 73.3370 \\
0.95 & 21.3880 & 32.7667 & 44.0129 & 66.7463 & 70.6403 \\
1.00 & 20.3455 & 31.1286 & 41.5084 & 61.5168 & 64.4158 \\
\hline
\end{tabular}

\section{COMPARATIVE SIMULATION RESULTS}

The four angles strings are saved in look up tables LUT of MATLAB/ Simulation to be used with a suitable logic combination to generate the PWM pulses at the mentioned angles that to execute the Selective Harmonic Elimination PWM (SHE PWM) technique. To evaluate the SHE PWM based inverter performance, Total Harmonics Distortion (THD), and harmonics spectrum of the load voltages are compared with the counterparts of Constant Switching Frequency PWM (CSF PWM) based inverter at all of the angles strings separately considering the same number of switching angle for each case. Table II shows the inverter parameters including the switching frequencies. 
Table 2. Inverter setting parameters

\begin{tabular}{ccc}
\hline Parameter & SHE PWM Based Inverter & CSF PWM Based Inverter \\
\hline DC link Voltage (V) & $350 \mathrm{~V}$ & $350 \mathrm{~V}$ \\
Load & $12 \Omega$ & $12 \Omega$ \\
Rated Power & $5 \mathrm{~kW}$ & $5 \mathrm{~kW}$ \\
Modulation Index (MI) & 0.9 & 0.9 \\
L-Filter & $12 \mathrm{mH}$ & $12 \mathrm{mH}$ \\
$1^{\text {st }}$ Comparison & $\emptyset_{1}, \emptyset_{2}, \emptyset_{3}$ & $f_{S W}=300 \mathrm{~Hz}$ \\
$2^{\text {nd }}$ Comparison & $\emptyset_{1}, \emptyset_{2}, \emptyset_{3}, \emptyset_{4}, \emptyset_{5}$ & $f_{S W}=500 \mathrm{~Hz}$ \\
$3^{\text {rd }}$ Comparison & $\emptyset_{1}, \emptyset_{2}, \emptyset_{3}, \emptyset_{4}, \emptyset_{5}, \emptyset_{6}, \emptyset_{7}$ & $f_{S W}=700 \mathrm{~Hz}$ \\
$4^{\text {th }}$ Comparison & $\emptyset_{1}, \emptyset_{2}, \emptyset_{3}, \emptyset_{4}, \emptyset_{5}, \emptyset_{6}, \emptyset_{7}, \emptyset_{6}, \emptyset_{7}$ & $f_{S W}=900 \mathrm{~Hz}$ \\
\hline
\end{tabular}

Figure 3 shows the comparison of the inverter output voltage with its Fast Fourier Transform FFT analysis of the harmonics spectrum between the SHE PWM and the CSF PWM of the constant switching frequencies as explained in Table II. From Figure 3, the low order harmonics elimination is clearly noticeable with respect to the designed angles of SHE PWM compared to the undesirable low order harmonics using CSF PWM. More over, the higher values of the voltage fundamentals are demonstrated using SHE PWM.

Figure 4 summarizes the comparison in term of inverter voltage shape with FFT analysis using Table II parameters setting. Figure 4 clearly demonstrates the priority of the harmonic elimination technique comparing to the conventional sinusoidal PWM technique.

Figure 5 add other explanation of the simulation results in term of THD\% levels and the fundamental voltage level through which the advantages of using SHE PWM are also shown.

Figure 6 shows load currents waveforms with FFT comparison at modulation index MI=0.9 for the case of SHE PWM of nine angles and CSF PWM of $900 \mathrm{~Hz}$ constant switching frequency, Figure 6 demonstrates the data of $5 \mathrm{~kW}$ rated power load current waveforms through which the effectiveness of SHE PWM over CSF PWM is shown in term of THD and fundamental current levels.

Figure 7 demonstrates the positive effect and the priority of using SHE PWM in term of fundamental current component and THD \% levels for high power applications. Inverter performance is explained during increasing the load power, and the technique of SHE PWM is preferred to use fdue to the low switching losses through the lower number of switches commutations per fundamental period [1]

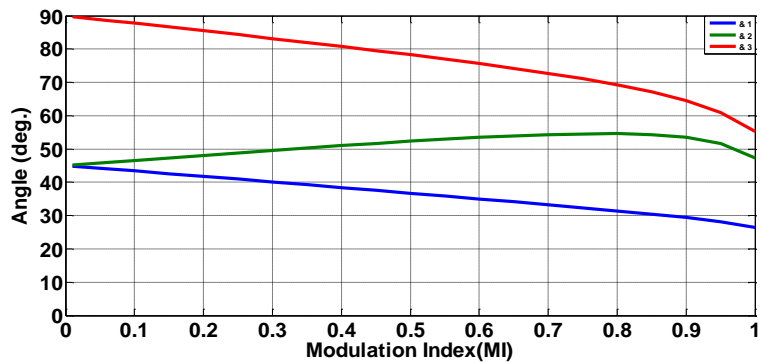

(a)

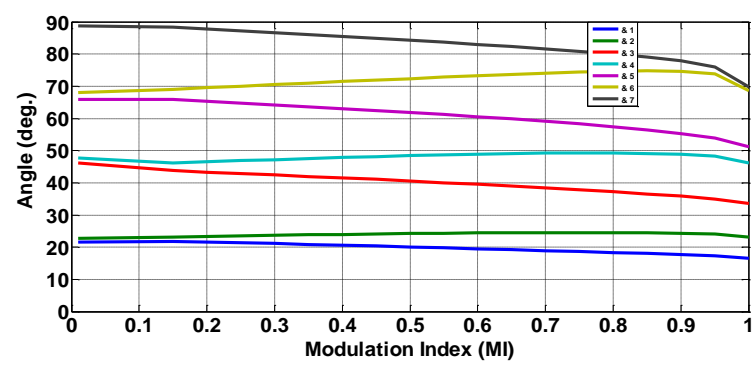

(c)

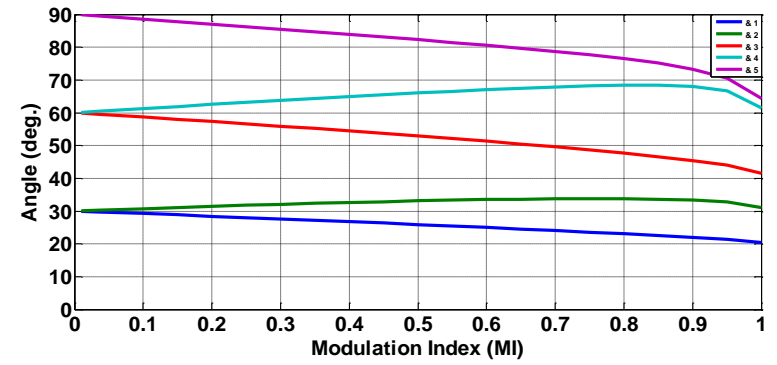

(b)

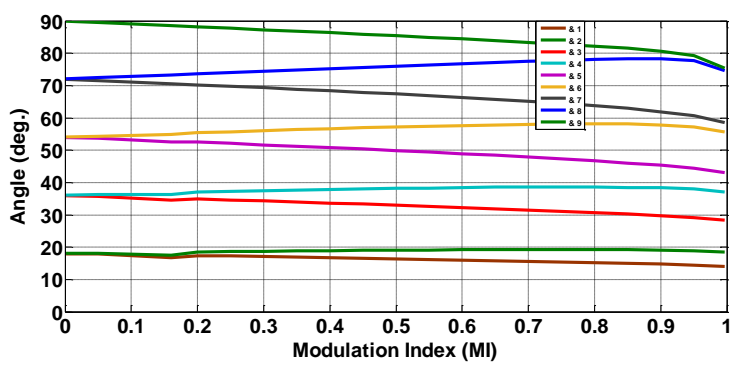

(d)

Figure 3. Four strings of angles as a selective harmonics elimination solution at different modulation indices; (a) Three angles, (b) Five angles, (c) Seven angles, (d) Nine angles 

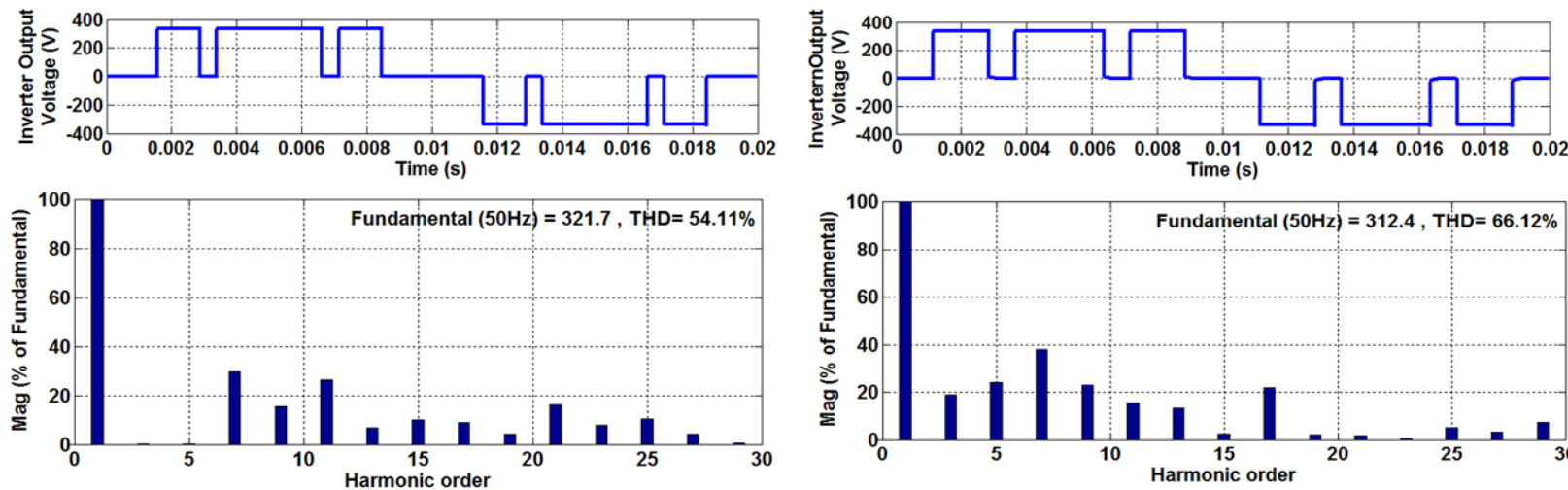

SHE PWM (3 Angles)
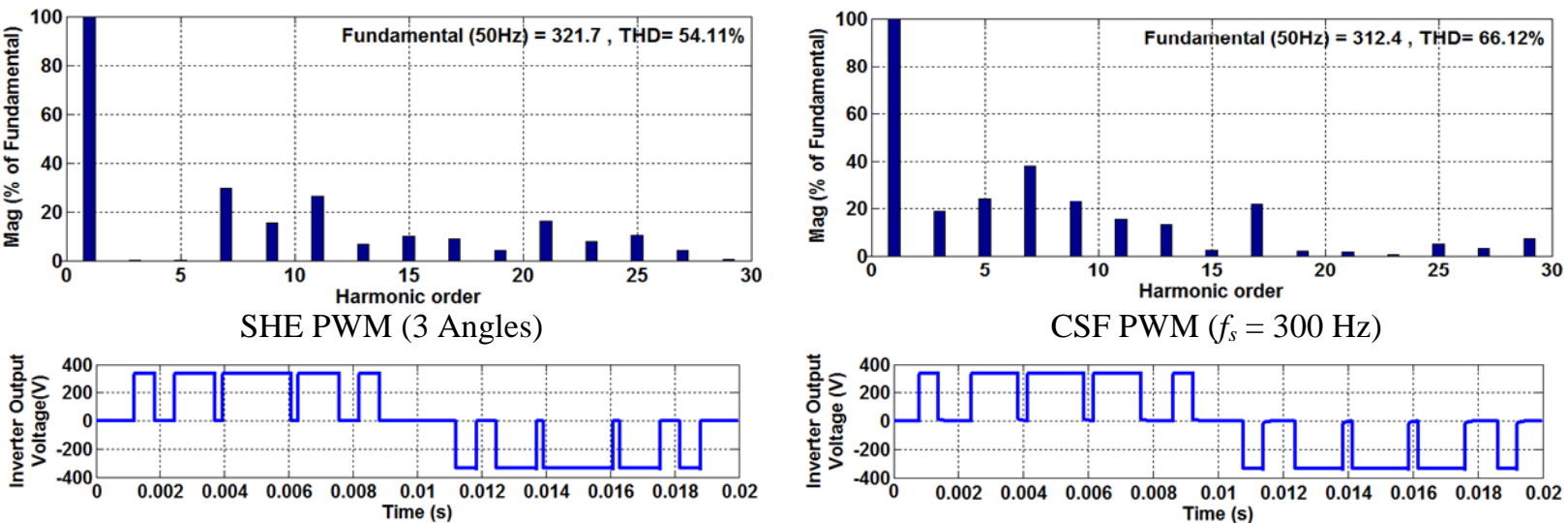

CSF PWM $\left(f_{s}=300 \mathrm{~Hz}\right)$
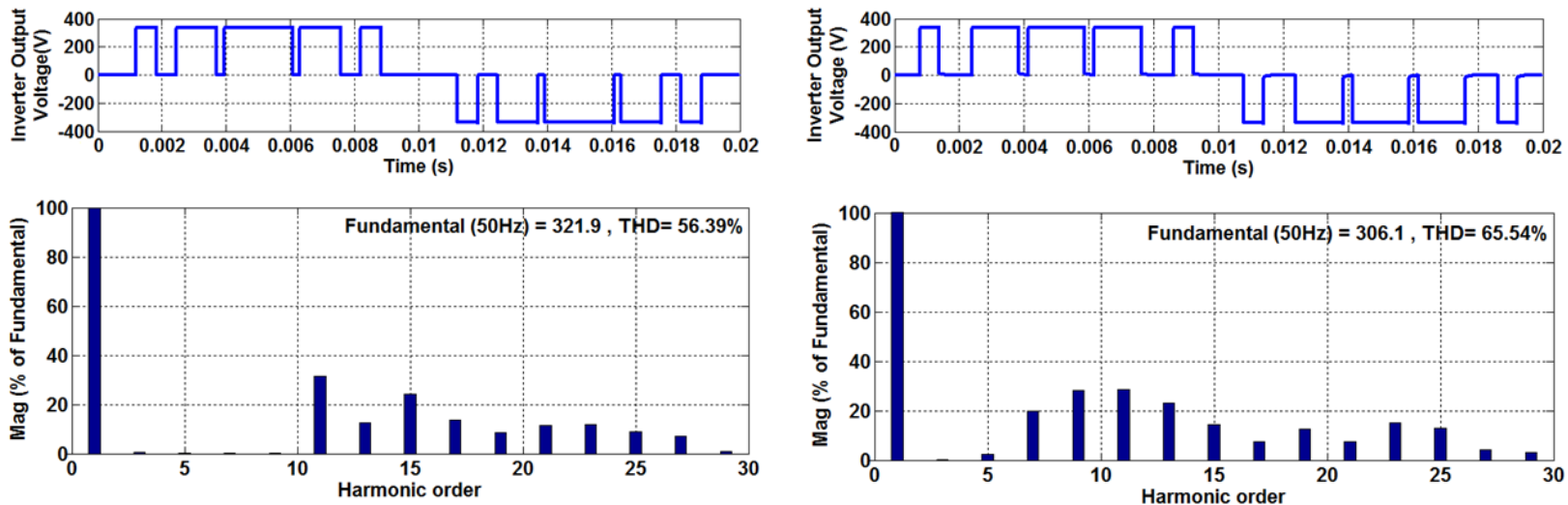

SHE PWM (5 Angles)

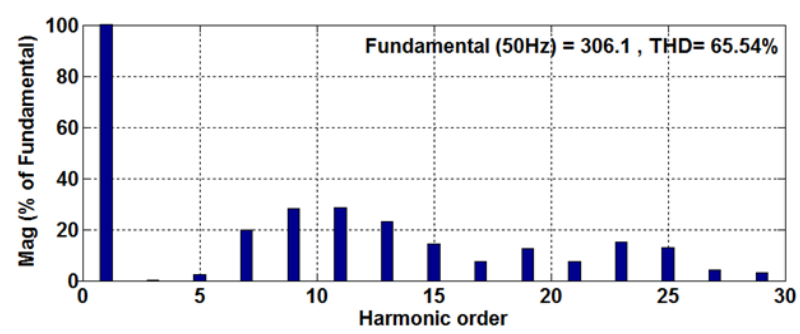

CSF PWM $\left(f_{s}=500 \mathrm{~Hz}\right)$
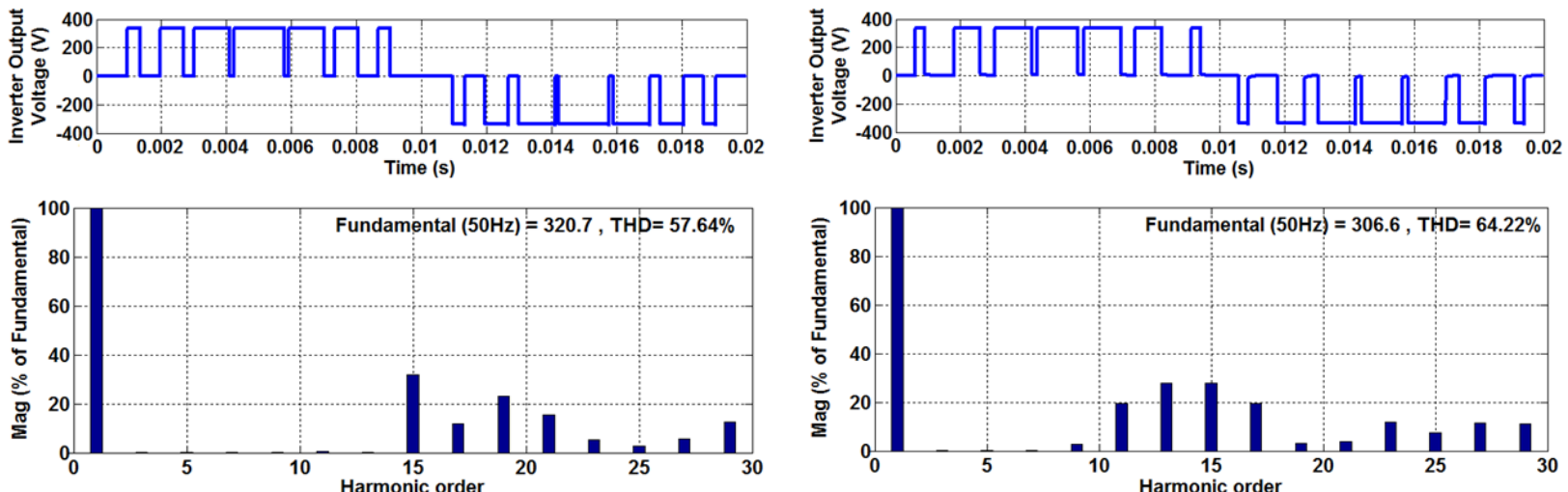

SHE PWM (7 Angles)

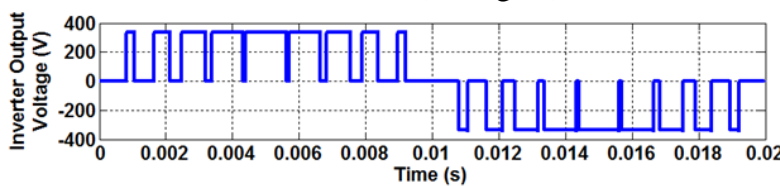

CSF PWM $\left(f_{s}=700 \mathrm{~Hz}\right)$
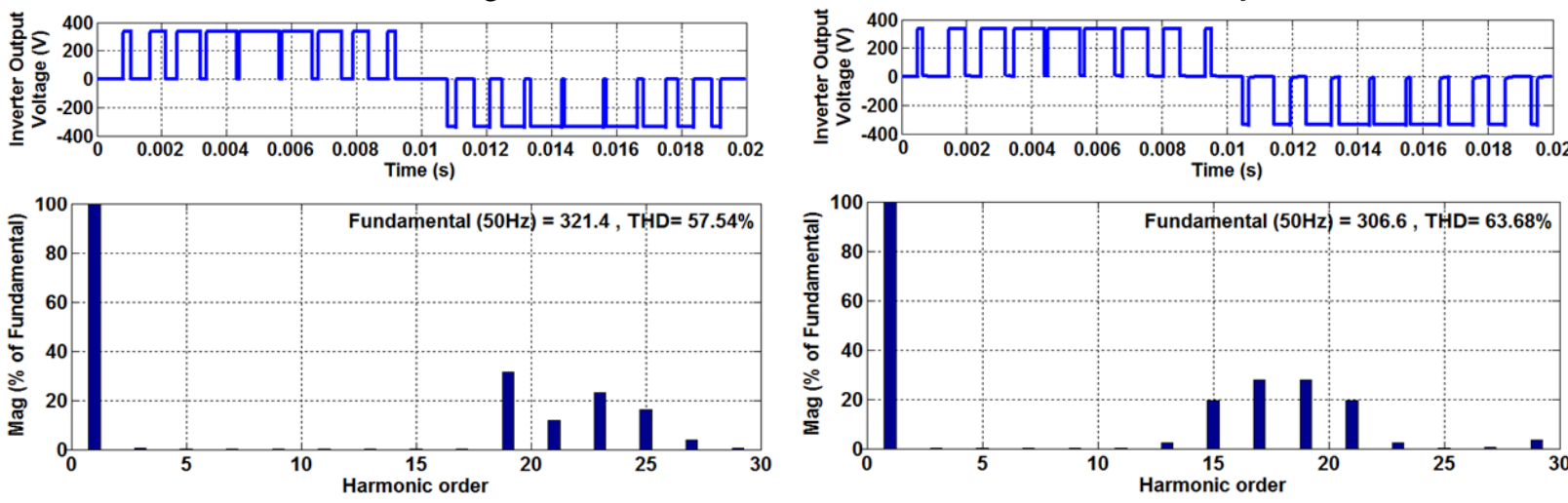

SHE PWM (9 Angles)

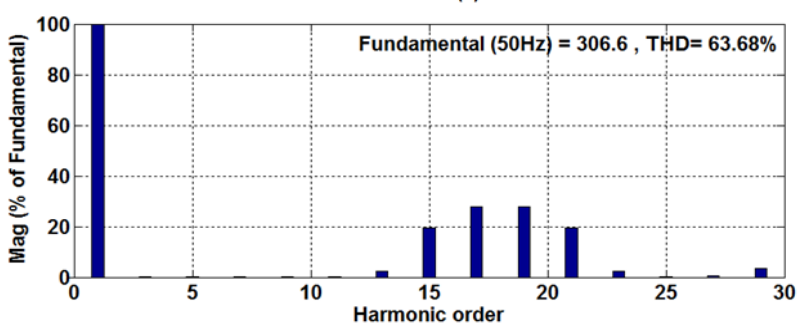

CSF PWM $\left(f_{s}=900 \mathrm{~Hz}\right)$

Figure 4. Inverter performance comparison in term of output voltage shape, harmonic spectrum, THD level, and fundamental component values; SHE PWM (left side), and CSF PWM (right side) 


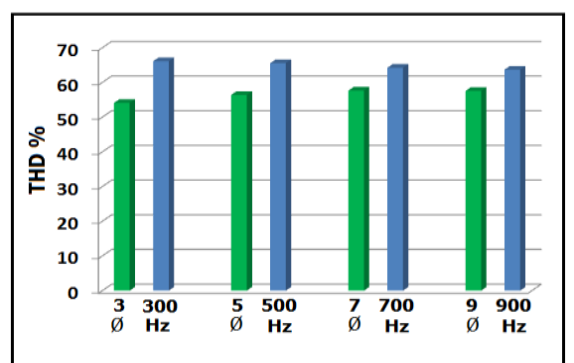

(a)

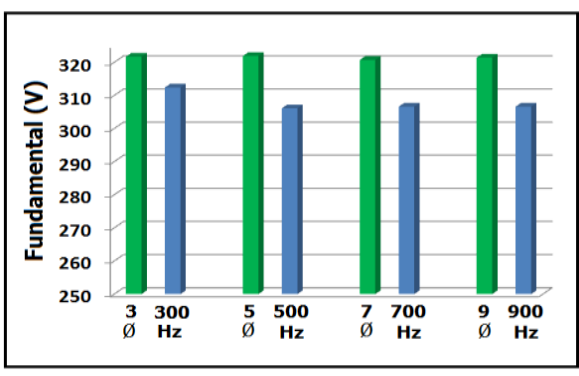

(b)

Figure 5. Comparison between SHE PWM and CSF PWM based inverter performance term; (a) Inverter Voltage THD\% levels, (b) Fundamental voltage levels
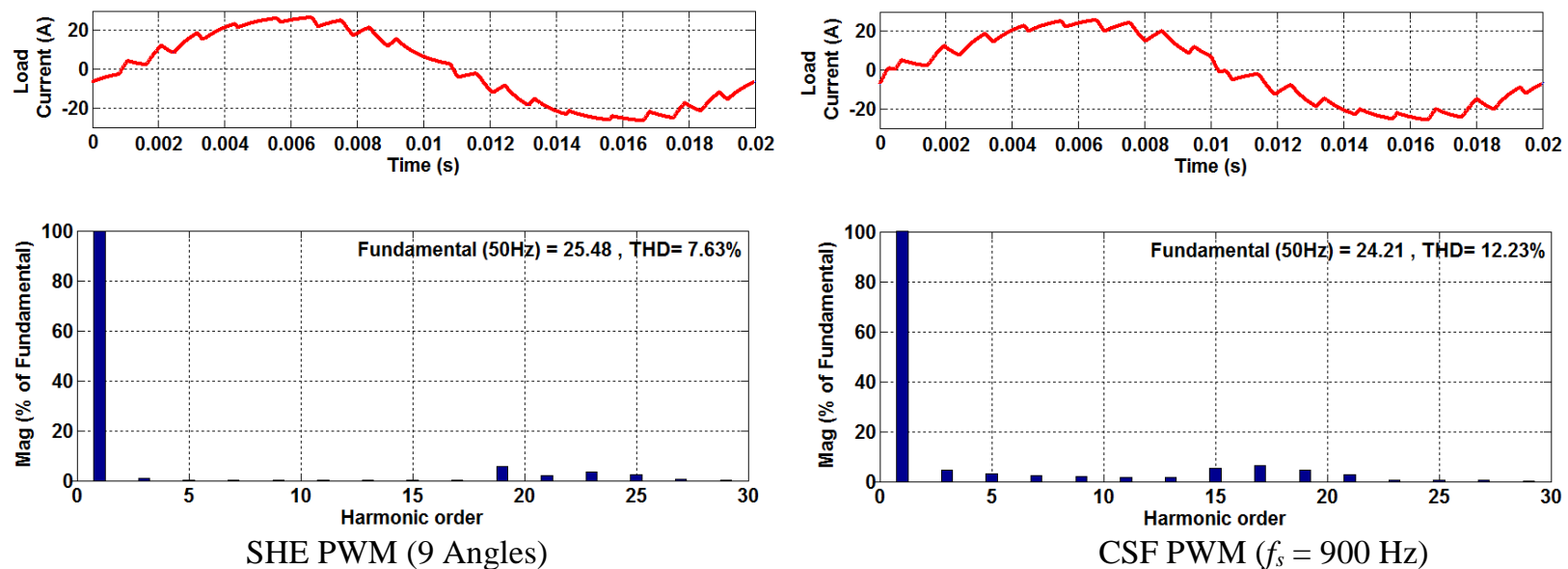

Figure 6. Inverter performance comparison in term of load current, and harmonic spectrum

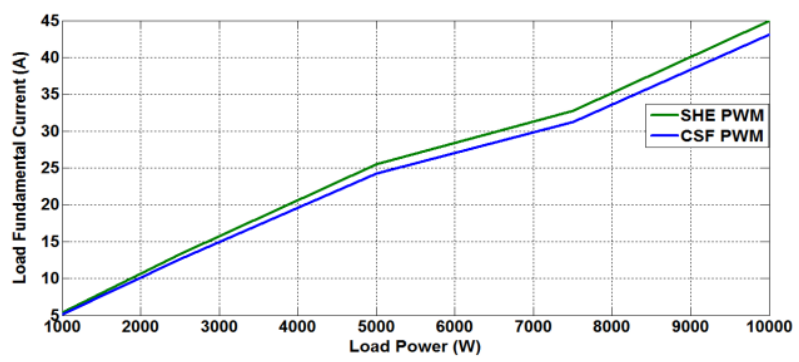

(a)

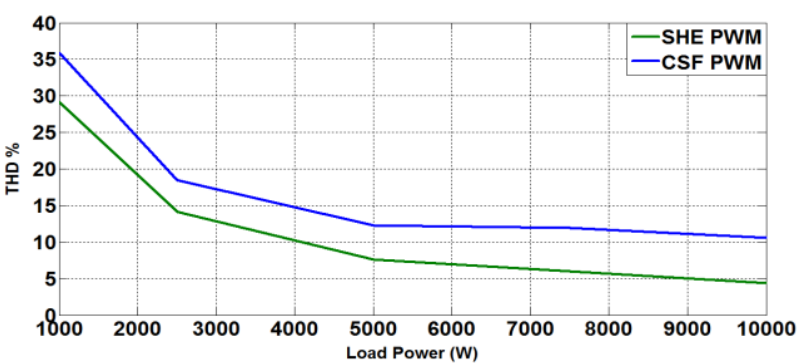

(b)

Figure 7. Inverter performance comparison at different load power in term;

(a) Fundamental current component, (b) THD \% levels

\section{CONCLUSION}

Complete steps of SHE PWM solutions generation and single-phase unipolar inverter function investigation with performance effectiveness evaluation based on SHE PWM, and comparing with CSF PWM based inverter all are presented in this paper. Four groups of angles are generated by deriving sets of nonlinear equations and then different strings of angles for different modulation indices are determined using the five-iteration numerical method of Newton-Raphson, the collected angles are plotted and the effects are analyzed. MATLAB/Simulink is used to save these angles in look-up tables (LUT) and with a suitable logic combination; SHE PWM pulses are generated to drive the inverter switches. The inverter output voltage and load current through L-filter are evaluated by the comparison with the counterpart of CSF PWM in term of 
harmonic spectrum, fundamental component, low order harmonic components levels and THD levels. Based on the number of generated switching angles, the constant switching frequency of CSF PWM is fairly selected such as $300 \mathrm{~Hz}$ for the case of three angle whereas $900 \mathrm{~Hz}$ for the case of nine angles. The collected simulation results are demonstrated the merits of SHE PWM over CSF PWM and clearly explained for the case of load power increasing that to provide a suitable reference study which indicate the positive effect of SHE PWM for high power applications.

\section{ACKNOWLEDGEMENTS}

The authors appreciate the financial support provided by school of engineering, American University of Ras Al Khaimah - UAE, www.aurak.ac.ae/en/school-of-engineering/

\section{REFERENCES}

[1] HA Attia, TKS Freddy, HS Che, WP Hew, A El Khateb, "Confined Band Variable Switching Frequency Pulse Width Modulation (CB-VSF PWM) for Single-Phase Inverter with LCL Filter", IEEE Transactions on Power Electronics, 2016.

[2] HA Attia, HW Ping, Y Al-Mashhadany, "Design and analysis for high performance synchronized inverter with PWM power control", Clean Energy and Technology (CEAT), 2013 IEEE Conference, 265-270.

[3] Hussain A. Attia, Yousif I. Al-Mashhadany, Beza N. Getu, "Design and Simulation of a High Performance Standalone Photovoltaic System," ICREGA'14 - Renewable Energy: Generation and Applications, Springer Proceedings in Energy 2014, pp 683-697.

[4] Attia Hussain, Sagafinia Ali, "Novel Discrete Components Based Speed Controller for Induction Motor", International Journal of Power Electronics and Drive Systems (IJPEDS), Vol. 7, Iss. 4, (2016).

[5] H Attia, BN Getu, N Hamad, "A Stable DC Power Supply for Photovoltaic Systems", Int. J. of Thermal \& Environmental Engineering 12 (1), (2016) 67-71.

[6] Hussain A Attia, Amjad Omar, Maen Takruri, "Design of decentralized street LED light dimming system", Electronic Devices, Systems and Applications (ICEDSA), 2016 5th International IEEE Conference, 2016.

[7] Hussain A. Attia, "Comparative Design of Fuzzy Logic Controller for Photovoltaic Panel Maximum Power Point Tracking”, 2017 International Conference on Electrical and Computing Technologies and Applications (ICECTA), 978-1-5386-0872-2/17/\$31.00 (2017 IEEE

[8] H Attia, A Omar, M Takruri, HY Ali, "Pulse Width Modulation Based Decentralized Street LED Light Dimming System”, International Journal of Power Electronics and Drive systems (IJPEDS) , 8(3), 2017, pp. 1238-1247.

[9] L. Li, D. Czarkowski, Y. Liu, and P. Pillay, "Multilevel Selective Harmonic Elimination PWM Technique in SeriesConnected Voltage Inverters “, industry Applications Conference, 1998, USA, doi: 10.1109/IAS.1998.730334

[10] K.A. Rani Fathima, and Dr.T.A. Raghavendiren, "Design of a Novel Control Scheme for the Converters of the Single Phase Unified Power Flow Controller Using Selective Harmonic Elimination”, 3rd International Conference on Power, Control and VLSI Engineering (ICPCVE'2014) Jan. 5-6, 2014 Dubai (UAE), pp. 28-35

[11] Mohamed Azab, "Harmonic Elimination in Three-Phase Voltage Source Inverters by Particle Swarm Optimization", Journal of Electrical Engineering \& Technology Vol. 6, No. 3, pp. 334 341, 2011DOI: 10.5370/JEET.2011.6.3.334

[12] Jason R. Wells, Xin Geng, Patrick L. Chapman, Philip T. Krein, and Brett M. Nee, "Modulation-Based Harmonic Elimination", IEEE Transaction on power Electronics, vol 22, no. 1, Jan. 2007, pp. 336-340

[13] K. Tamilarasi, C. Suganthini, "Neural Network Based Optimal Switching Pattern Generation for Multiple Pulse Width Modulated Inverter", International Journal of Modern Engineering Research (IJMER), Vol.3, Issue.4, Jul Aug. 2013, pp-1910-1915

[14] Jamal A. Mohammed, "Optimum Solving SHEPWM Equations for Single Phase Inverter Using Resultant Method", Engineering \& Technology, Vol. 26, No.6, 2008, pp.660-670

[15] M. Kiran kumar, A. Madhu Sainath, V. Pavan Kumar, "Selective Harmonic Elimination by Programmable Pulse Width Modulation in Inverters", International Journal of Engineering Trends and Technology (IJETT), Vol. 4, Iss. 4, April 2013, pp. 1196-1201

[16] Jiajia Ren Jianze Wang Yinghong Hu Yanchao Ji, "Research on Solutions to Selective Harmonic Eliminated PWM Switching Angles for Novel Five level Inverter", Power and Energy Engineering Conference (APPEEC), 2010 AsiaPacific, doi: 10.1109/APPEEC.2010.5449029

[17] Ayong Hiendro, "Multiple Switching Patterns for SHEPWM Inverters UsingDifferential Evolution Algorithms", International Journal of Power Electronics and Drive System (IJPEDS), Vol.1, No.2, December 2011, pp. 94 103

[18] N. Bahari, Z. Salam, Taufik, "Application of Differential Evolution to Determine the HEPWM Angles of a Three Phase Voltage Source Inverter", 36th Annual Conference on IEEE Industrial Electronics society, Nov. 2010, USA, pp. 2683-2688

[19] O. Bouhali, M. Berkouk, B. Francois, C. Saudemont, S. Labiod, "Solving Harmonics Elimination Problem in ThreePhase Voltage controlled Inverter using Artificial Neural Networks", Journal of Electrical Systems, 1-1 (2005): pp. $39-51$

[20] Wahidah Abd Halim, Tengku Noor Ariana Tengku Azam, Komathi Applasamy, Auzani Jidin, "Selective Harmonic Elimination Based on Newton-raphson Method for Cascaded H-bridge Multilevel InverterInternational Journal of Power Electronics and Drive System (IJPEDS), Vol. 8, No. 3, September 2017, pp. 1193 1202 
[21] D. Grahame Holmes, "Pulse Width Modulation For Power Converters; Principles and Practice”, IEEE Press, A John Wiley \& Sons, Inc., Publication, 2003.

[22] Sun J, Grotstollen H (1992) Solving nonlinear equations for selective harmonic eliminated PWM using predicted initial values. IEEE Trans Power Electronics pp.259-260

\section{BIOGRAPHY OF AUTHOR}

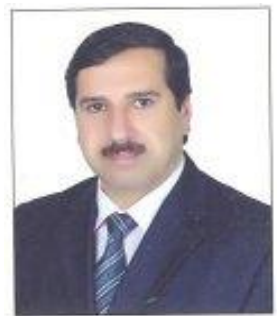

Hussain Attia earned his M.Sc. degree in electronic engineering from the University of Technology, Baghdad, in 1999. He earned his B.Sc. in electronic and communication engineering from the same university in 1991. Hussain's research interests: Power Electronics System, AC \& DC Speed Control Drives, Analog \& Digital Electronic Circuits Design, PWM Inverters (single phase \& three phases). 